\title{
Allen James Lowrie (10 October 1948 - 30 August 2021)
}

KeVIn F. KenneAlly $•$ School of Agriculture and Environment $•$ University of Western Australia

-Perth•Australia・kevin.kenneally@uwa.edu.au

Allen James Lowrie, a member of the International Carnivorous Plant Society, passed away on 30 August 2021, aged 72, after a short illness. He was a world authority on carnivorous plants, styleworts and triggerplants. Born at Mount Hawthorn in Western Australia, he spent his early childhood in Mosman Park before the family moved to Mount Hawthorn. His parents, Winnifred and Alan, were in the fashion industry, which was probably an indication of where Allen's creativity and artistic flair came from. Growing up in Yokine, there were childhood memories of playing barefoot in the bush, making cubby houses and in teenage years riding bikes to hang-out at Lake Monger, where he made a canoe out of corrugated iron.

Beginning work at the age of 15 , he forged a successful commercial career, turning his hand to advertising, steel fabrication, working as a geologist's assistant in the Pilbara, and eventually started a business constructing below-ground swimming pools. In 1971, Allen married long-time girlfriend Pauline See and daughters Trinity and Filicity soon followed. Allen always acknowledged the part Pauline played in whatever he did. They were certainly a formidable couple when it came to exploring remote places. Pauline would be seen assisting Allen with his field work activities and helping to press and catalogue his numerous plant collections.

Allen's philosophy on life was largely shaped by a close call with compulsory enrolment for national service (or conscription) into Australia's armed forces during the unfortunate saga of the Vietnam War. From an early age, it drove him to follow his great passion for botany, to be outgoing, to take risks, to profit from his own endeavours and to strive to succeed, but always having fun and adventures along the way. During his commercial career, he invented a range of pool chlorinators and $\mathrm{pH}$ controllers. The success of these inventions and his thriving business allowed him to leave the commercial world in 1987 to focus full-time on his studies of Australian carnivorous plants (Aldrovandra, Byblis, Cephalotus, Drosera, and Utricularia), styleworts (Levenhookia), and triggerplants (Stylidium).

Australia is home to over one third of all carnivorous plants species that are currently known worldwide, and this amazing concentration is far greater than any other continent or country. Australia also boasts two endemic carnivorous plant genera that occur no-where else on earth. This became Allen's challenge; to collect and describe the many new species that awaited discovery. Though not formally trained in botany, Allen persevered in his research studies to become a truly accomplished botanist, working both solo and alongside mentors and colleagues in the plant sciences to make botanical pursuits his life's work. He forged a close relationship with Dr Rica Erickson, described by noted botanist Dr Alex George as "one the foremost amateur natural historians in Western Australia in the 20th Century". Rica enjoyed plant collecting and made very accurate drawings from living specimens. She had published a series of books; 'Orchids of the West' (1951), 'Triggerplants' (1958) and 'Plants of Prey in Australia' (1968). Rica encouraged Allen to continue her studies of carnivorous plants and triggerplants. Like Rica, Allen was an accomplished artist, drawing and photographing plants from living material, providing the many botanical drawings and illustrations for his books and papers. He also built a series of glass and shade houses so that he could study plants and do long-term studies of their growth and flowering. He encouraged other carnivorous plant enthusiasts world-wide to experiment with cultivating Australian species, often with them producing outstanding results. 
He also established a successful business, supplying seeds and tubers that he cultivated at his home in Duncraig.

Discovery in a highly synthetic field like systematic/evolutionary botany involves multiple observations, rather than a concerted effort to elucidate a few facts by means of a definitive experiment as in many areas of experimental biology. Allen was a botanist really attuned to observing diversity, so much so, that it became a lifetime obsession. Allen maintained a private working collection of herbarium specimens for comparative taxonomic research. This saved him from having to commute to the Western Australian Herbarium on a regular basis to compare material, although Allen did visit the herbarium and assisted with the curation of the Drosera specimens housed there. It was Allen's wish that his specimen collection, known as the 'Herbarium Lowrieanum' be transferred to the Western Australian Herbarium on his death.

Also encouraged by Rica's 'Triggerplants' book was Professor Sherwin Carlquist, an American botanist, plant anatomist and photographer, who visited Western Australia in 1962 and found Rica's 'Triggerplants' book in a Perth bookstore. He described the book as having "the appealing charm that only someone genuinely enthusiastic about a hobby can confer". Carlquist went onto describe many new Australian triggerplant species. In the early 1990s, Allen and Sherwin would collaborate in describing a new species of Drosera, as well as a number of species of Stylidium. Carlquist described Allen as "an amateur botanist whose enthusiasm was rather like that of Rica Erickson".

Allen was also fortunate to be also mentored by Associate Professor Sidney (Sid) James, a cytogeneticist in the Botany Department at the University of Western Australia. Sid had a passionate

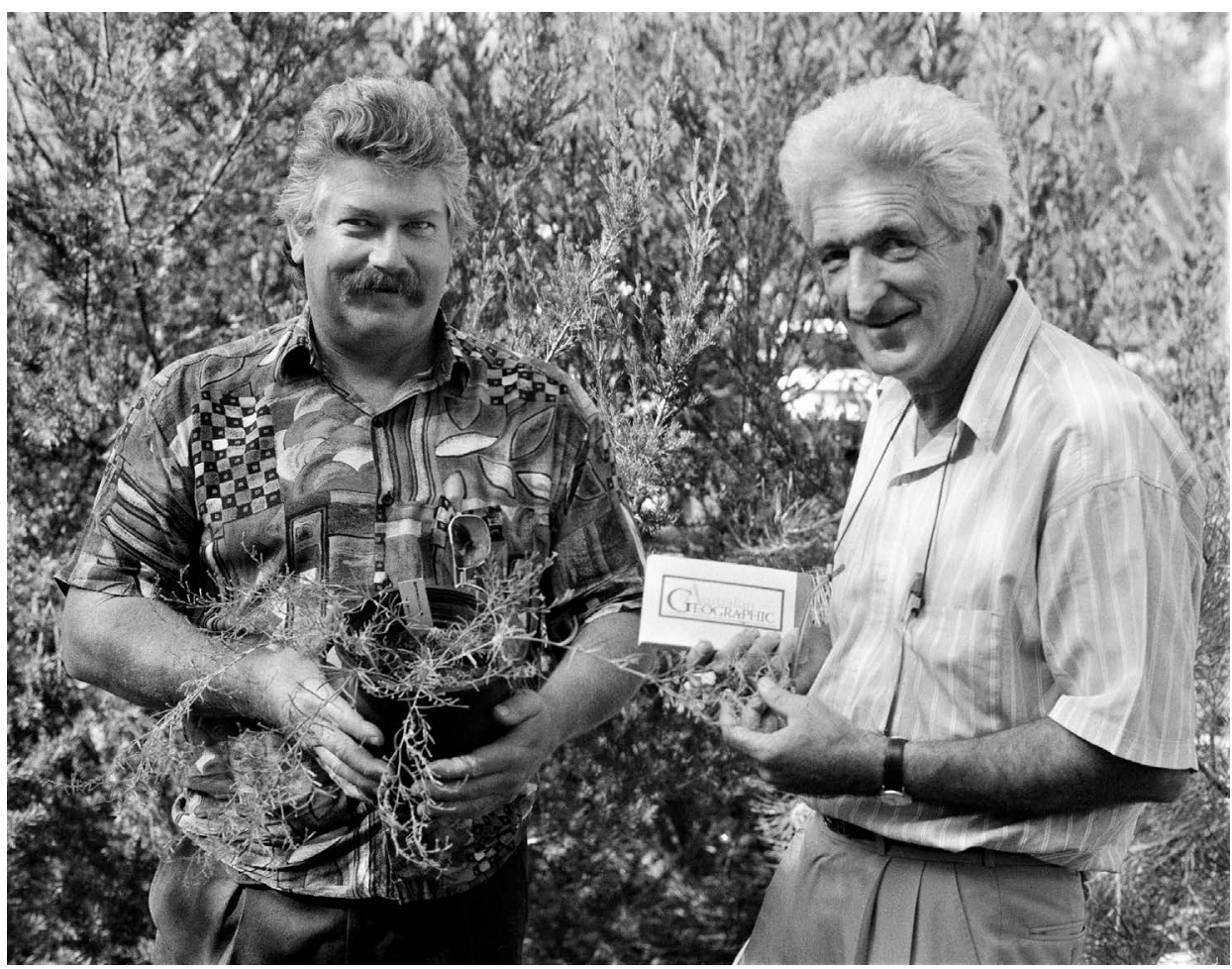

Allen Lowrie (left) with mentor, Associate Professor Sidney (Sid) James. 
interest in the evolution of the Australian flora and was keen to encourage his students and individuals, like Allen, in their pursuits in this field. He conveyed to Allen the importance of understanding the variation existing in wild populations as being the key to sound taxonomy and an essential step in developing informed management for conservation. He also emphasised the need for scientific rigour, including the collection of adequate vouchers and documentation of study populations. Sid taught Allen how to do chromosome counts on Drosera and Stylidium.

Armed with this information, Allen conducted botanical surveys across Australia, including Cape York Peninsula and the Kimberley, some of the most remote places in Australia. He also made expeditions to Borneo and Sumatra, as well as Malaysia, with the assistance of Robert Oliver and Steve Rose to study tropical pitcher plants (Nepenthes). Allen wrote that: "We travelled from Padang to Lake Toba, exploring mountains and roadsides along the way. We were fortunate enough to join up with the Nepenthes study husband and wife team from Canada, John Turnbull and Anne Middleton. John had selected some great locations, the highlight of which was Mount Talang, Sumatra, Aia Batumbuak in West Sumatra, Indonesia. It was on this summit where we camped for the night. Just at dusk we heard the sound of a big cat. A tiger was in close proximity. We all slept with one eye open that night".

Remote areas are not always welcoming. They are sometimes dangerous, but the worst part of fieldwork is the uncertainty of not finding what you are searching for. He would take his family on holidays to far flung places, but of course that always involved making plant collections of some description. Oh, and on any trips, he never took food from home, not when you could buy sausages and hot chips from servos and roadhouses!

Between 1987 and 1998, Allen published a three-volume treatise, 'Carnivorous plants of Australia', published by the University of Western Australia, documenting all Australian carnivorous plants known at that time. When the last book of the set was released in 1998, the three volumes had become the most highly respected, most popular and certainly the most valuable of all carnivorous plant publications produced at that time. In 1992, Allen collaborated with Dr Neville Marchant from the Western Australian Herbarium in describing 34 taxa of Western Australian tuberous and pygmy Drosera species published in the prestigious Kew Bulletin. During the intervening 25 years since the publication of the original three volumes, Allen continued to undertake intensive field work and make observations, discovering many new Australian carnivorous plants. He carefully revised, updated, and improved his original books and in 2013, his life's work was released in three volumes as 'Carnivorous Plants of Australia Magnum Opus'.

During his botanical career Allen made 1,121 collections that are lodged in the Western Australian Herbarium (PERTH). He named 150 new taxa that are accepted today (Drosera 78, Stylidium 62, Byblis 5, Utricularia 4, and Levenhookia 1) plus 17 which are considered synonyms now. He made a number of new combinations (Drosera 24 and Stylidium 3). His name is honoured in two carnivorous plant species Drosera lowriei, Utricularia lowriei, a triggerplant (Stylidium lowrieanum), and a smut fungus growing on Byblis rorida (Yelsemia lowrieana).

Aside from his many botanical achievements, Allen spent countless hours corresponding with carnivorous plant enthusiasts and scientists across the globe and was always happy to share his vast knowledge, especially eager to assist young beginners. He gave numerous lectures to botany students, wildflower enthusiasts, naturalist club members, and the Kimberley Society, as well as contributing many scientific papers naming the many new species of plant that he has discovered.

In the early 1990s, Allen collaborated with Professor Kevin Kenneally (The University of Western Australia) and Dr David Coates (Western Australian Herbarium) on a series of taxonomic papers 
describing new species of Stylidium. He also collaborated with Dr John Conran (The University of Adelaide) in describing new species of Drosera and Byblis.

Allen was a distinctive combination of period blokeyness (often politically incorrect), intellectual substance, a high level of energy, natural combativeness (which could turn into a grudge), and a high-octane instinct for spotting new plant species. He called it as he saw it. There was no holding back. He had a wicked sense of humour that he shared around the campfire and a great belly-laugh. On field trips his snoring was legendary and he was banished to the outer perimeter of the camp site. One night, his snoring was so loud, a female member of the party, who could not sleep due to the noise, walked over to him and shone a head-torch in his face, attempting to wake him up. Allen later re-counted that he awoke to a bright white tunnel of light and a face hovering over him. He was convinced he had died and was entering heaven! When he realised what was happening, he was not at all impressed at being woken!

Beyond his botanical pursuits, Allen was a loving husband, a doting father and grand-father, a keen musician, playing guitar, rhythm, lead and bass, the mandolin, and keyboards. He wrote music for pleasure and composed and recorded no fewer than 30 songs. Prospecting for gold was another hobby that he enjoyed with some success, later becoming a partner with Steve Rose in a number of gold tenements in the Murchison District of Western Australia.

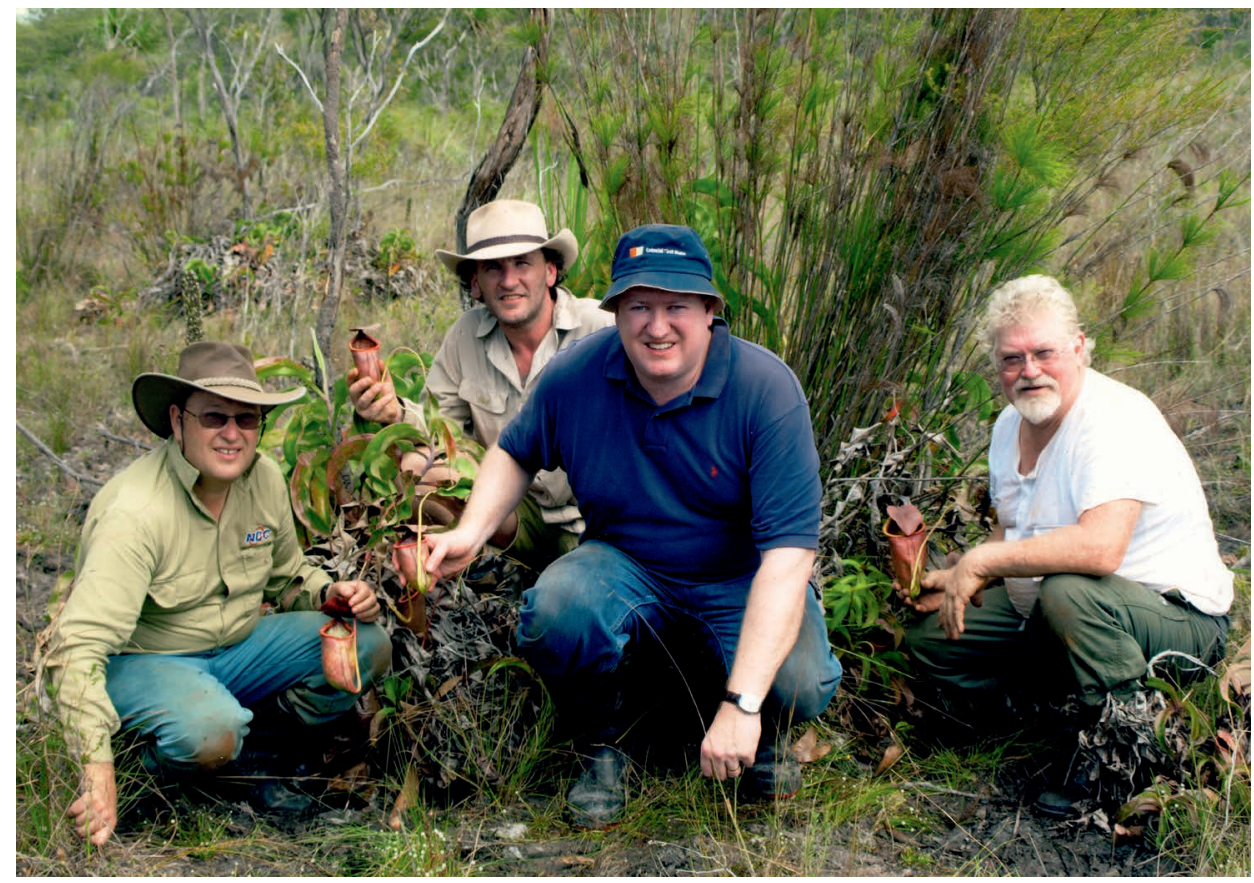

L-R: Denzel Murfet, Stuart Mcilroy, Richard Nunn, and Allen Lowrie pictured with a large plant of Nepenthes rowaniae, in August 2008 on Cape York, Queensland, Australia. Photo by Stuart Mcilroy. 